\title{
Designing and Modeling of Control Strategies Based on Multi-Objective Optimization for a PMSG Wind Turbine: A Study Based on the Grid Errors and Wind Speed
}

\author{
Ehsan Ganji ${ }^{1 *}$, Mehdi Mahdavian², Iman Eshaghpour ${ }^{3}$, Mojtaba Janghorban ${ }^{1}$ \\ 1 Acecr Institute of Higher Education, Kermanshah, Iran \\ 2 Department of Electrical Engineering, Naein Branch, Islamic Azad University, Naein, Esfahan, Iran \\ 3 Department of Electrical Engineering, Kashan Branch, Islamic Azad University, Kashan, Iran \\ * Corresponding author's e-mail: mr.ehsanganji@gmail.com
}

\begin{abstract}
In this paper, an independent wind energy conversion system was studied with the control strategies used to provide power specifically to the areas far from the grid. In this research, three strategies are designed and used in order to stabilize the output. This system contains a directed rectifier which is responsible for maximum power point tracking. Additionally, a common DC bus and a fully controlled inverter were designed. An LC filter was also used in the system in order to eliminate switching harmonics to a considerable extent and provide a reliable noiseless source for load supply. Since the power demand and the produced power of the turbine are variable and indistinguishable in each moment, a depletion load is also placed in the system. In this study, it was observed that the designed strategies prove the output stability in different sections and under different conditions with resonators and non-linear PI and PID controllers. The designed strategies were also supported by the simulation results.
\end{abstract}

Keywords: wind turbine, permanent-magnet synchronous generator (PMSG), output stability of the turbine, resistive depletion load, voltage damping, Reduction of switching harmonics.

\section{INTRODUCTION}

In recent years, the existing energy sources have been studied by energy politicians, compelling a search for new energy sources including the wind. Although there are large wind farms currently working to produce power in national grids, another field regarding the energy of wind is also emerging. Autonomous wind turbines are new trends in the power production for distant spots or separate sites in which connection to the grid is very expensive or even impossible. Multivariable control systems can also be used to adjust the power of the generator and minimize the load on the rotor blades in high wind speeds [1]. Reversible integration in grids can be faced with the problems connected with the disruption abilities in the grid. These problems might be power quality, frequency or voltage functions [2]. Using compliance control- lers with the presence of unbalanced loads which are subject to sudden changes, guarantees the stability of the three-phase source [3]. In autonomous wind turbines, the turbine system should be ready for any situation. These situations usually depend on the employed control strategies. Even the disruptions of different power qualities can be identified and eliminated using wavelet transformation analysis [4]. The empirical results in [5] imply that the experiment can be effective on a separate load in the real time of the behavior of a wind energy conversion system (WECS) by a digital signal processing (DSP) model. In the field of renewable energies, three aspects of wind energy were investigated: the status, the potentials and the evaluation and analysis policies [6]. In order to improve the adjustment of the DCbus voltage significantly, the SC storage was performed regarding load conditions and wind 
speed fluctuations using a buck-boost converter. Moreover, the stability of the three-phase voltage source of the energy system, the DC-link power and the voltage control were studied line by line [7]. A multipurpose system was designed in a wind turbine emulator (WTE) to develop and examine new control strategies for wind energy conversion systems. This multipurpose system was designed using a processing module to control a separate DC motor. The core of the processing module of the DSP system is used for a structure that easily provides the changes of wind speed and turbine parameters and supervision over system variables [8]. The classic control of the slow dynamics with respect to the mechanical dynamics of the drive is a new solution in commercial wind turbines, which proves that a dynamic control can help speed up the adjustment and observe a significant comparison in the aerodynamic efficiency with a normal control process. Basically and in theory, dynamics control is better than non-classic control, which leads to higher efficiency and reliability [9]. The mechanical tensions in the turbine are improved based on the repair and maintenance demands and the average time between failures. In order to achieve these goals, the signal of the control loop without a speed sensor can be adequately controlled in a reference speed using a constant-slope ramp signal and a certain algorithm [10]. Under the condition of wind speed imbalance, the turbine can be adequately controlled without any tensions or problems by designing nonlinear and dynamic rotor field and flux controllers and a wind turbine speed controller using sliding mode techniques, the fuzzy logic, maximum power point tracking and the uncertainty state [11].

An energy storage system (ESS) installed on a power system can effectively control the oscillations of the power system with active power or the ESS reaction in power systems [12]. Maximum power point tracking (MPPT) can ensure the reliability of the output power of the system completely by extracting the maximum power from the wind turbine using the search algorithms and by controlling the DC-DC converter in the PWM and in the DC-AC converter under the condition of wind speed imbalance [13]. The grid-side converter is constantly working to control the supply and production of electric power and prevent the supply of harmonics and the reactive power by the nonlinear load in the PCC [14]. The pulse width modulation (PWM) $[15,16]$ is used by the space vector modulation (SVM) in the sliding mode to control power converters. In addition, controlling the power factor in the output of power converters can help optimize the system in the most efficient way. While analyzing a PMSM it was indicated that the electromagnetic torque can be increased with respect to the angle between the stator and the rotor flux and the torque response by increasing the rotational speed of the stator flux. Moreover, a DTC method was used on the drives of the PMSM in a specific switching mode inside the PMSM. The empirical results show that the torque response is much faster with this method [17]. The dynamic machine model can help improve the stability of the power system at the time of disruptions by properly reducing the modeling in constant and variable speeds of a large wind turbine with an asynchronous generator [18]. In [19], three modulation strategies were presented for matrix conversion based on mathematical principles under the conditions of unbalanced input voltage. On the other hand, a strategy was developed in three different ways based on the construction and the vector modulation inverter. By properly adjusting the modulation index of the inverter vector, the output voltage of the matrix conversion remains sinusoidal and balanced. Various power electronic converters that are connected to the grid (between the generator and the load) and work based on harmonic compensation are still considered as substantial challenges in the energy production system [20]. Some effective strategies can be designed to improve the quality of the power system by taking into account the insular problems in renewable storage systems. A better use of semiconductors and a flexibility control can obtain a higher quality modulation ratio in higher powers by controlling a separate DC-link (instead of a VSI) [21]. The direct torque control (DTC) strategy with the optimization of the matrix conversion (MC) cycle based on the permanent-magnet synchronous motor (PMSM) can always have a significant effect by low-torque waves without any need for the harmonic changes of rotation and a constant switching frequency [22]. Internal model control (IMC) can fully access the set-point tracking and discard any disruptions for the compensation of load distortions, which can be obtained by the conversion of the matrix vector of the induction motor (IM) control supply and the disruption of the input voltage, dis- 


\section{Nomenclature}

\begin{tabular}{|l|l|l|l|}
\hline$V_{W}$ & wind speed, $\mathrm{m}^{-1}$ & $P_{S}, Q s$ & active and ractive statoric powers / W (var) \\
\hline$\rho$ & air density, $\mathrm{kg} \mathrm{m}^{-1}$ & $T_{e m}$ & PMSG torque, $\mathrm{m}$ \\
\hline$R$ & blade radius & $d, q$ & synchronous reference frame index \\
\hline$\lambda$ & tip-speed ratio & $I_{t 1}, I_{t 2}, I_{t 3}$ & inverter output currents \\
\hline$C_{p}$ & power coefficients & $I_{L 1}, I_{L 2}, I_{L 3}$ & load currents \\
\hline$P_{a}$ & aerodynamic power, $\mathrm{W}$ & $R_{L 1}, R_{L 2}, R_{L 3}$ & load resistances \\
\hline$T_{a}$ & aerodynamic torque, $\mathrm{N} \mathrm{m}$ & $L_{L 1}, L_{L 2}, L_{L 3}$ & load inductances \\
\hline$\Omega_{t}$ & aeroturbine rotor speed, rad s ${ }^{-1}$ & $U_{d c}$ & DC bus voltage \\
\hline$\Omega_{m}$ & generator speed, rad s ${ }^{-1}$ & $I_{i n v}$ & inverter input current \\
\hline$\Omega_{S}$ & synchronous generator speed, rad s ${ }^{-1}$ & $R_{S}, R_{r}$ & stator and rotor Resistances, $\mathrm{X}$ \\
\hline$C_{t}$ & filter capacitance & $L_{S}, L_{r}$ & stator and rotor Inductances, $\mathrm{H}$ \\
\hline$J$ & turbine total inertia, $\mathrm{kg} \mathrm{m}^{2}$ & $L_{m}$ & mutual inductance, $\mathrm{H}$ \\
\hline$G$ & gearbox ratio & $U_{C 1}, U_{c 2}$ & line - to - line voltages \\
\hline$\omega_{S}$ & synchronous speed, rad/s & $U_{m 1}, U_{m 2}$ & inverter voltages \\
\hline
\end{tabular}

turbance rejection and the optimization of the dynamic performance of the motor drive using IMC [23]. A VFC can meet the demands of the reactive power of an asynchronous generator along with load leveling, harmonic elimination, voltage adjustment and load balancing [24].

By comparing the response of control systems with ADRC controllers, many researchers believe that control engineering might be ready to break into the new generation of controllers from the classic PID controller [25]. There is no need for the complete details of the system model to design a nonlinear adaptive controller (NAC), since this area is capable of adaptation and resistance to the uncertainty of system parameters, system dynamics and external disturbances [26].

\section{THE DESCRIPTION OF THE STUDIED CONTEXT AND CONTROL STRATEGIES}

\section{The turbine model}

The context studied to evaluate the performance of a 2 megawatt autonomous wind turbine was simulated with the use of a PMSG which was coaxially connected to a back-to-back converter. This system also contained a directed rectifier which is responsible for maximum power point tracking, a common DC bus and a directed power inverter. Following the inverter, an LC filter was placed in the system to attenuate all switching harmonics while working and to provide a noiseless sinusoidal voltage source for the three-phase

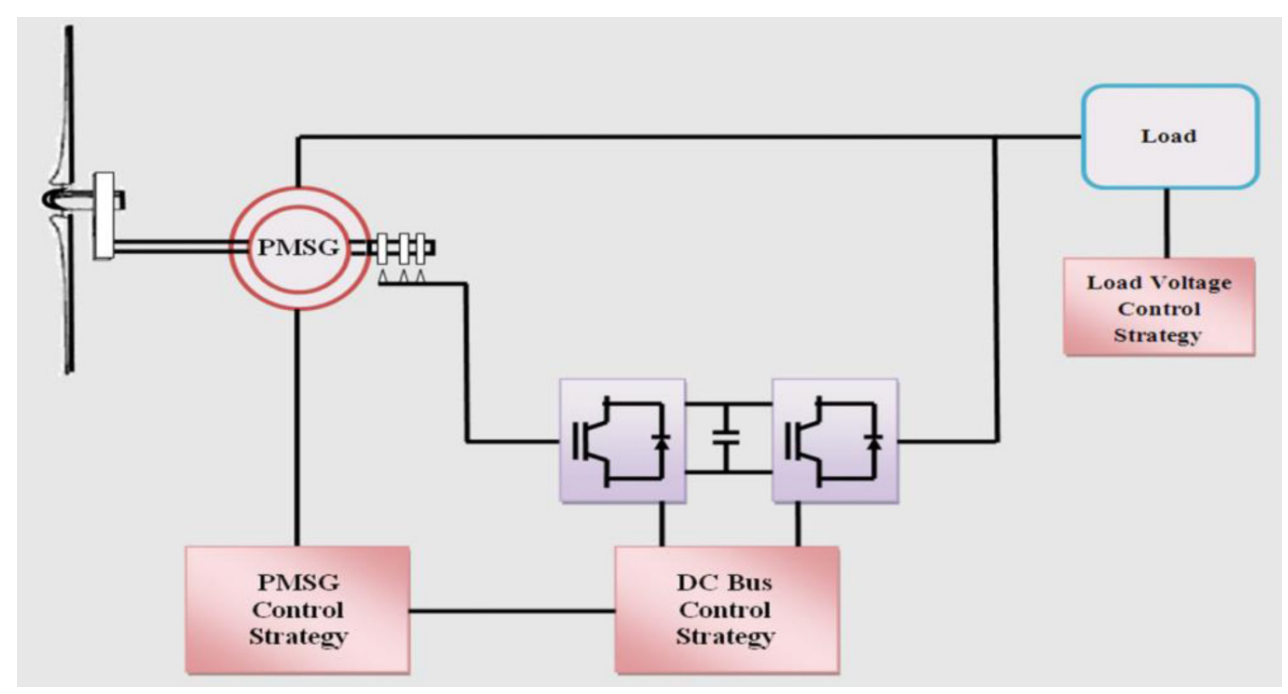

Fig. 1. The structure of the studied context 
load supply. Since the load power demand was variable and the amount of power produced by the turbine was unpredictable, a depletion load was used through a chopper in the DC-bus strategy. In the case of mass production, the excess energy is directed to the depletion load. This is the case we have studied in our experiments.

The aerodynamic power anticipated for the wind turbine is as follows [11].

$$
P_{a}=0.5 \rho \pi R^{2} V_{W}{ }^{3} C_{P}(\lambda, \beta)
$$

In the equation above, $C_{P}$ is the coefficient of a nonlinear function which is given in the following:

$$
C_{P}(\lambda)=a_{0}+a_{1} \lambda+a_{2} \lambda^{2}+a_{3} \lambda^{3}+a_{4} \lambda^{4}+a_{5} \lambda^{5}
$$

In which:

$$
\lambda=\frac{R \Omega_{t}}{V_{w}}
$$

That

$$
C_{T}(\lambda, \beta)=\frac{C_{p}(\lambda, \beta)}{\lambda}
$$

A simple and practical model for the air flow rate is given in the following based on [11].

$$
\mathrm{V}_{\text {ride }}=\mathrm{V}_{\mathrm{nt}}+\frac{(c-45)\left(V_{s t}-V_{n t}\right)}{95-45}
$$

Figure 1 illustrates the complete structure of the proposed system. In the following chapter, the control strategies will be discussed according to table 1 .

\section{The PMSG control strategy}

The control strategy for the PMSG section is formed around the regulatory ring using $I_{S d}$ and $I_{s q}$ in the d-q component.

A first-order Park transform is used to write the equations for the $I_{a}, I_{b}$ and $I_{c}$ currents. Two designs for nonlinear PI controllers are used here in order to provide the equations of the stator currents by taking into account the values of the reference currents $I_{s d \text {-ref }}$ and $I_{s q-r e f}$. In the following, the vector control strategy describes the required equations for the reference currents of the PMSG:

$$
\left\{\begin{array}{l}
\mathrm{I}_{\text {sd_ref }}=0 \\
\mathrm{I}_{\text {sq_ref }}=\frac{\mathrm{T}_{\text {em_PMSG_ref }}}{\mathrm{p} \phi_{m}}
\end{array}\right.
$$

In which $T_{\text {em__PMSG_ref }}$ is the reference electromagnetic torque of the PMSG. This torque should have the following form in order to ensure the stability of the MPPT system in the PMSG:

$$
\mathrm{T}_{\text {em_PMSG_ref }}=\frac{\rho \pi \mathrm{R}^{5} \mathrm{C}_{\mathrm{pmax}}}{2 \lambda_{\text {opt }}^{3}} \Omega^{2}
$$

After writing the stator current equations, the stator voltages $V_{S d}$ and $V_{S q}$ for the proposed system are calculated in the Park reference frame as follows:

$$
\begin{gathered}
\mathrm{V}_{\mathrm{sd}}=\mathrm{R}_{\mathrm{s}} \mathrm{I}_{\mathrm{sd}}+\mathrm{L}_{\mathrm{s}} \frac{\mathrm{dI}_{\mathrm{sd}}}{\mathrm{dt}}-\rho \Omega \mathrm{L}_{\mathrm{s}} \mathrm{I}_{\mathrm{sq}} \\
\mathrm{V}_{\mathrm{sq}}=\mathrm{R}_{\mathrm{s}} \mathrm{I}_{\mathrm{sq}}+\mathrm{L}_{\mathrm{s}} \frac{\mathrm{dI}_{\mathrm{sq}}}{\mathrm{dt}}+\rho \Omega \mathrm{L}_{\mathrm{s}} \mathrm{I}_{\mathrm{sd}}+\rho \Omega \phi_{\mathrm{m}}
\end{gathered}
$$

In this design, the values and equations of the three-phase voltages $V_{a}, V_{b}$ and $V_{c}$ can be obtained through the equations of the inverse Park transform. Afterwards, the working periods are determined for different cases in order to produce three signals to control the rectifier in the PWM.

\section{The nonlinear control of the blade pitch}

First, we consider the definitions and the conditions of continuity for wind disturbances:

We define $z_{1}=x_{1}, z_{2}=\dot{x}_{1}$ and $z_{3}=\psi(x, z)$; thus, we obtain the following equations:

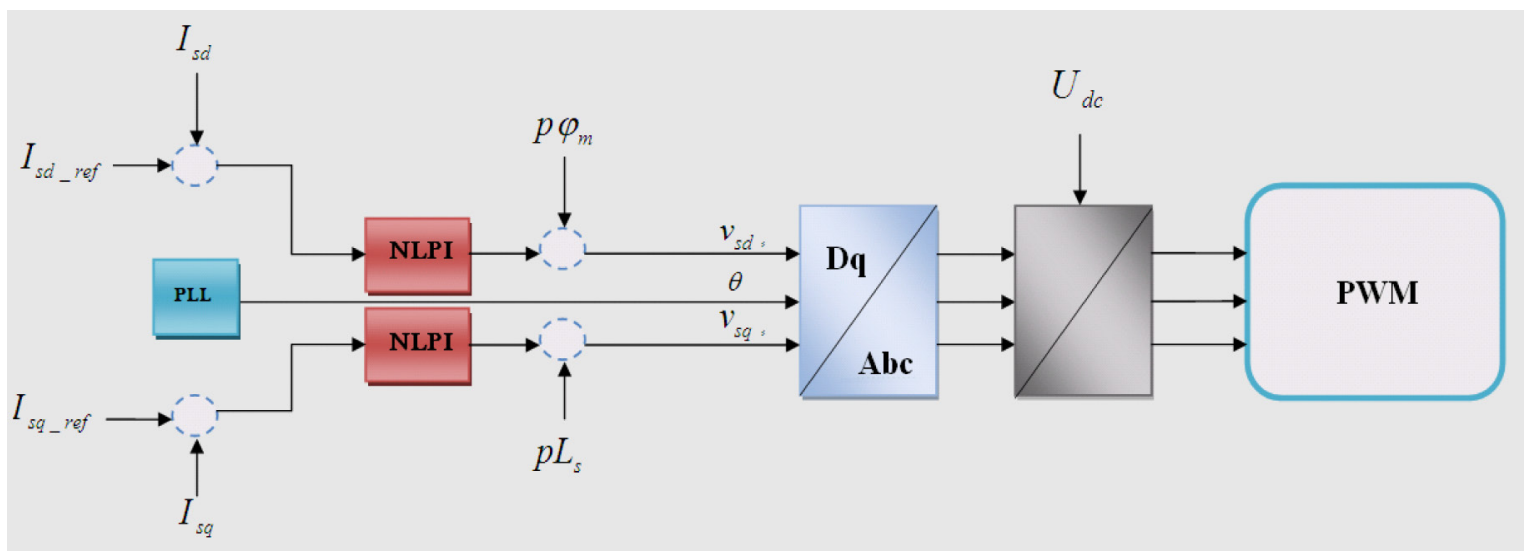

Fig. 2. The PMSG control diagram 
Table 1. The nonlinear controller and the FNLC parameters

\begin{tabular}{|l|c|}
\hline \multicolumn{1}{|c|}{ Parameters } & Value \\
\hline FLC/N-PI Proportional gain $\left(1 / \mathrm{s}^{2}\right)$ & 6.3 \\
\hline FLC/N-PI Integral gain $(1 / \mathrm{s}), \mathrm{ki}$ & 0.26 \\
\hline ESPO equivalent input gain $\left({ }^{\circ} \mathrm{s}^{3} / \mathrm{rad}\right), \mathrm{b}_{0}$ & 0.04 \\
\hline ESPO nonlinear coefficient $(\mathrm{rad} / \mathrm{s}), \mathrm{h}$ & 0.001 \\
\hline ESPO observer bandwidth, $\mathrm{a}_{0}$ & 40 \\
\hline ESPO estimation gain $(1 / \mathrm{s}), \mathrm{k} \mathrm{a}_{1}$ & $1.2 \times 102$ \\
\hline ESPO estimation gain $(1 / \mathrm{s} 2), \mathrm{k} \mathrm{a}_{2}$ & $4.8 \times 103$ \\
\hline ESPO estimation gain $(1 / \mathrm{s} 3), \mathrm{k}_{3}$ & $6.4 \times 104$ \\
\hline
\end{tabular}

$$
\left\{\begin{array}{l}
\dot{z}_{1}=z_{2} \\
\dot{z}_{2}=z_{3}+b_{0} u \\
\dot{z}_{3}=\Psi(x, t)
\end{array}\right.
$$

Considering $\widetilde{z}_{1}=z_{1}-\hat{z}_{1}$, we obtain a linear ESPO:

$$
\left\{\begin{array}{l}
\dot{\hat{z}}_{1}=\hat{z}_{2}+k_{01} \widetilde{z}_{1} \\
\dot{\hat{z}}_{2}=\hat{z}_{3}+b_{0} u+k_{02} \widetilde{z} \\
\dot{\hat{z}}_{3}=k_{03} \widetilde{z}
\end{array}\right.
$$

Considering $\hat{z}_{1}(i=1,2,3)$ and $\widetilde{z}_{1}$, an error is obtained for $z_{1}$. If $k_{0 i}$ is the parameter coefficient:

$$
\left[\begin{array}{lll}
k_{01} & k_{02} & k_{03}
\end{array}\right]=\left[\begin{array}{lll}
3 \alpha_{0} & 3 \alpha_{0}^{2} & 3 \alpha_{0}^{3}
\end{array}\right]
$$

In which $\alpha_{0}$ is the bandwidth observer of the only parameter being adjusted.

Thus, the wind speed of a nonlinear ESPO system can be estimated according to the following equations:

$$
\begin{aligned}
& \left\{\begin{array}{l}
\dot{\hat{z}}_{1}=\hat{z}_{2}+k_{01} \widetilde{z}_{1} \\
\dot{\hat{z}}_{2}=\hat{z}_{3}+b_{0} u+k_{02} \operatorname{fal}\left(\widetilde{z}_{1}, .5, h\right) \\
\dot{\hat{z}}_{3}=k_{03} \operatorname{fal}\left(\widetilde{z}_{1}, .25, h\right)
\end{array}\right. \\
& \operatorname{fal}(x, \sigma, h)=\left\{\begin{array}{l}
\frac{\sigma^{2}}{h^{(1-\sigma)}} x, \\
\operatorname{sign}(x) \sigma^{2}|x|^{\sigma}
\end{array}\right.
\end{aligned}
$$

In which $x$ is the input error, $\sigma$ is the index accuracy in the 0-1 range and $h$ is the width of the linear part of the nonlinear function.

Using the obtained equations and the results of the $\psi^{\wedge}(\mathrm{x})$ disturbances and the third-order ESPO, the $U$ input control is written in the following:

$$
u=\frac{1}{b_{0}}(v-\hat{\Psi}(x))
$$

$x_{1}$ is given in the following, considering the difference between the rotor speed and the reference speed:

$$
v=\left(k_{p}+\frac{k_{i}}{s}\right)\left(\omega_{r}^{*}-x_{1}\right)
$$

Finally, the nonlinear control of the control pitch is described as below:

$$
u=\frac{1}{b_{0}}\left(k_{p}+\frac{k_{i}}{s}\right)\left(\omega_{r}^{*}-x_{1}\right)-\frac{1}{b_{0}} \hat{\Psi}(x)
$$

The schematics of the nonlinear PI (N-PI) control system of the blade angle are illustrated in the figure above. By applying the results from table 1 , this system was designed by considering several purposeful plans in order to compensate for all the disruptions and shortcomings of nonlinear controllers.

\section{The DC-bus control strategy}

In the dynamic and control discussions of modeling studies, using a DC-bus in the structure of VSWTs provides the possibility of placing an ESS system which plays a role in the quality improvement of the power produced in all the collections at the time of disruption, in addition to the stability of the system. The DCbus control strategy leads to the balance between the two sides of the system stability and generally depends on the balance between the components and energy production. Due to the uncertainty and the dependency of the production on weather conditions, a control system for the ESS was also designed and simulated.

When the wind speed is high and excessive production occurs in the system, the depletion load in wind turbines is connected to the DCbus using a chopper, eliminating the effects of the excess power in the system. The PWM signal that controls this chopper is obtained by the nonlinear PI controller. This signal causes the DC-bus control to remain in the constant voltage which is intended for the system (400 


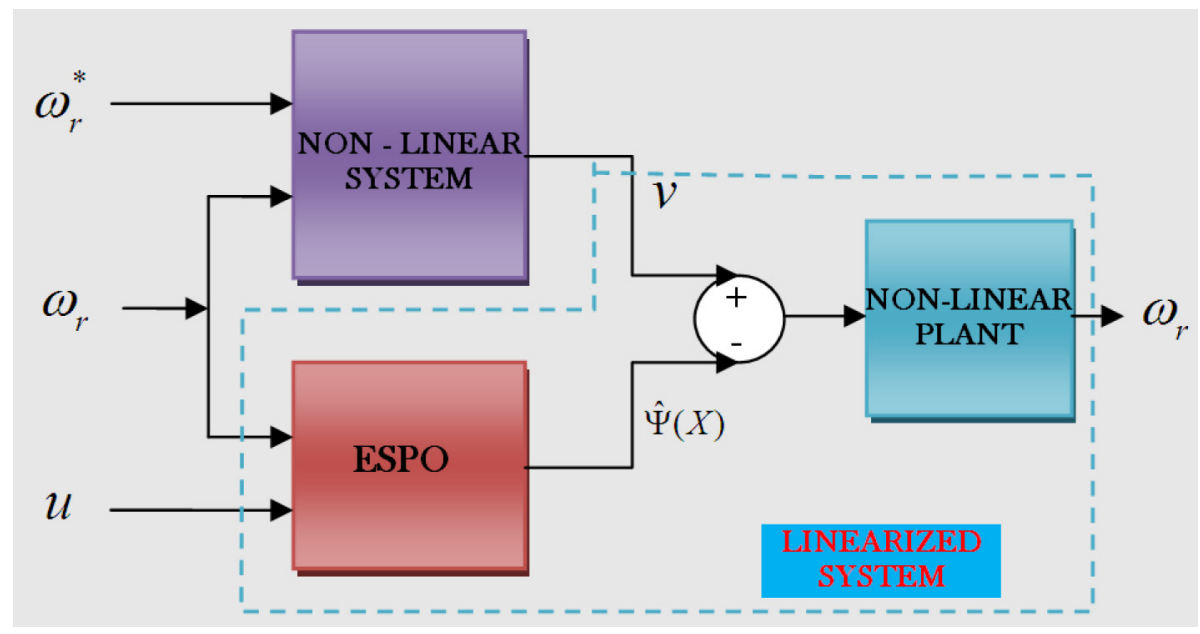

Fig. 3. The proposed nonlinear PI controller (N-PI)

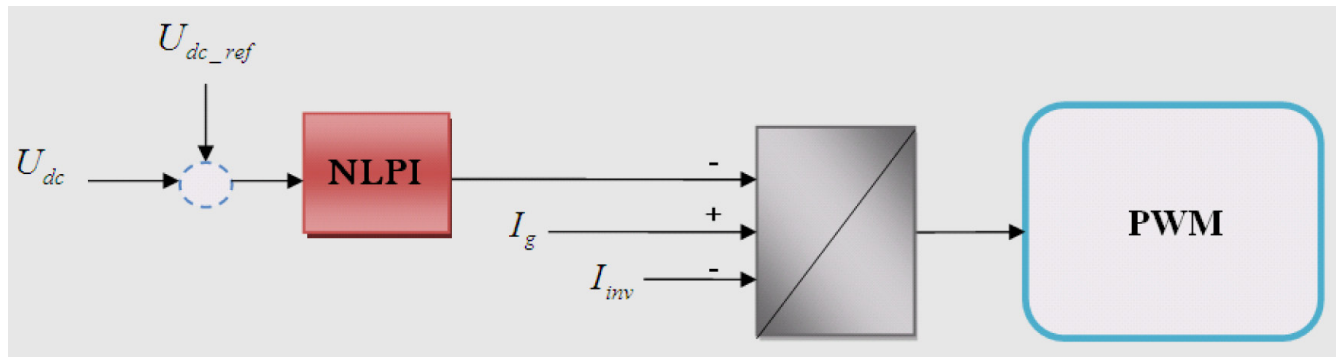

Fig. 4. An illustration of the DC-bus control

volts). Thus, we observed no changes in the output. However, in most systems, using an ESS leads to the conditions in which production can be fully controlled. Another solution for this case is the application of hybrid systems such as wind-diesel, wind-hydrogen and wind-photovoltaic-hydrogen systems. We are planning to carry out this investigation in another article in the near future.

\section{The load voltage control strategy}

In power systems, the output voltage control strategy uses an RLC filter to control the output. The $U_{c 1}$ and $U_{c 2}$ elements are used for adjusting and controlling the resonators. Using the control equation of $C_{r}(s)$ in this design is appropriate for adjusting the shape of periodic waves. The reference voltages $U_{c 1}$ ref and $U_{c 2}$ ref are considered to have the following form:

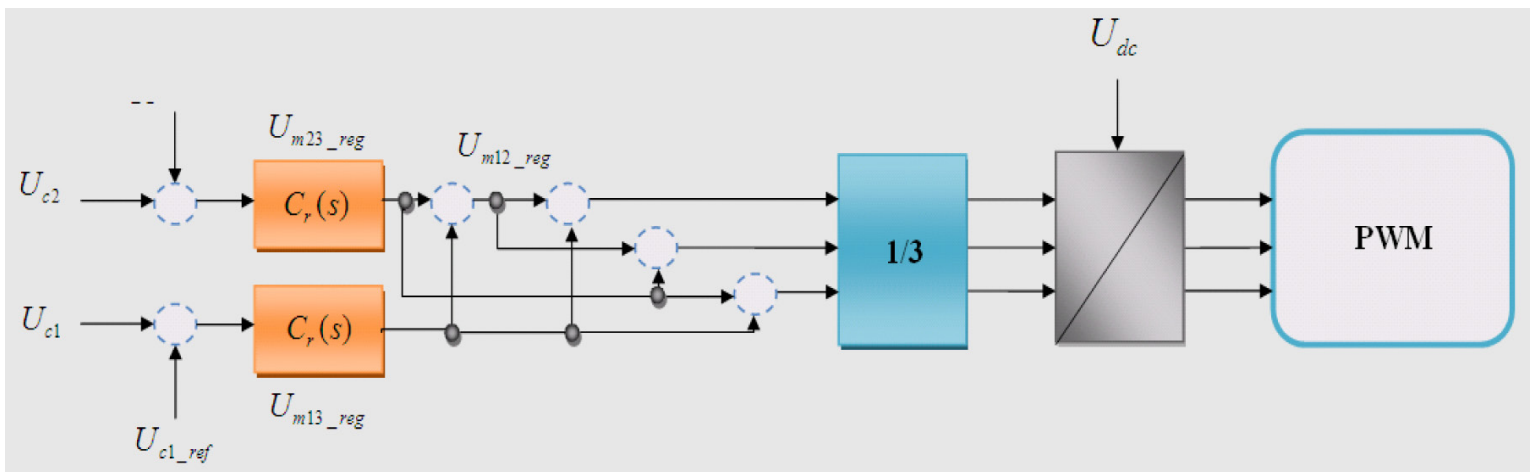

Fig. 5. An illustration of the load voltage control strategy 


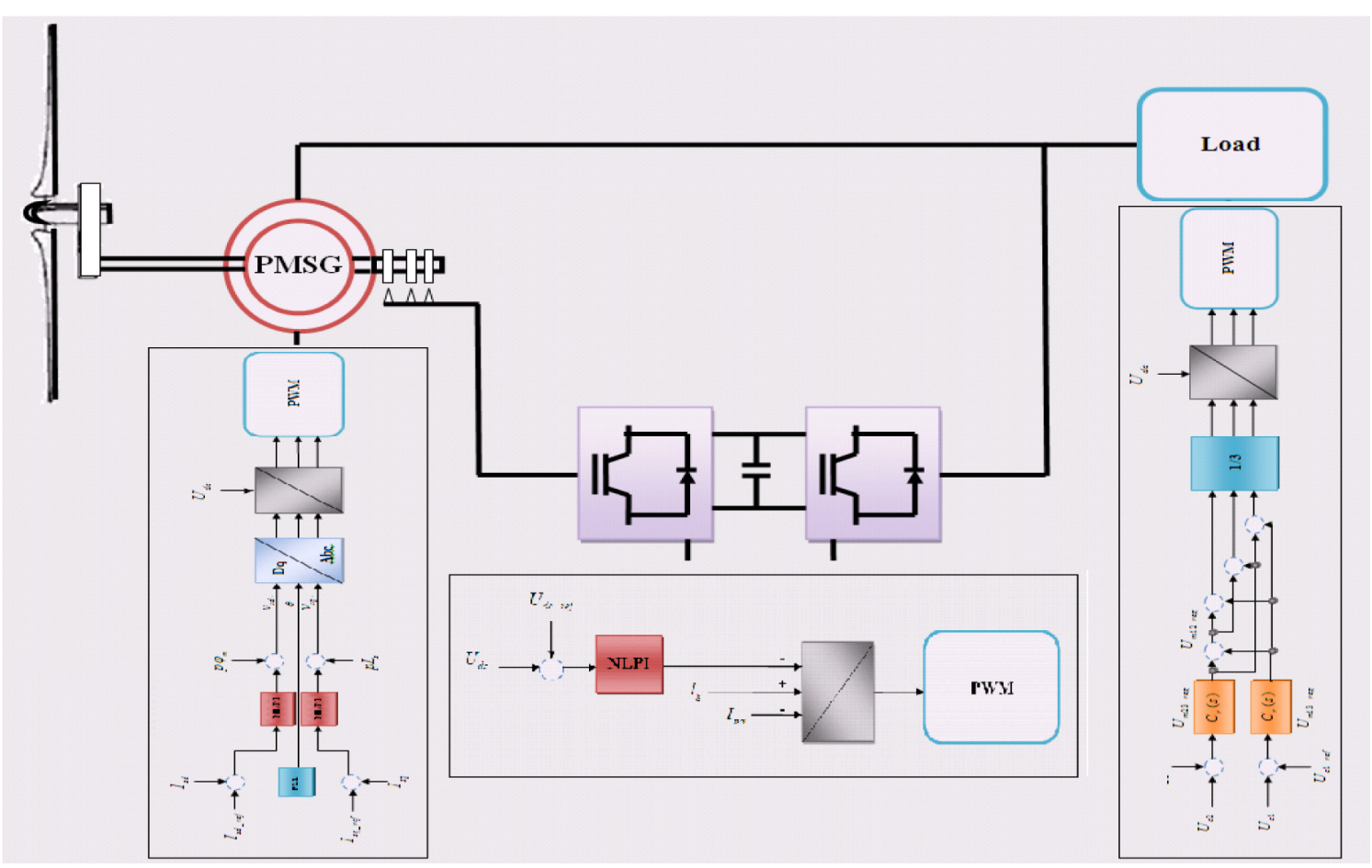

Fig. 6. The proposed design with a diagram of the controllers

$$
\left[\begin{array}{c}
\mathrm{U}_{\mathrm{c1} \_ \text {ref }} \\
\mathrm{U}_{\mathrm{c} 2 \_ \text {ref }}
\end{array}\right]=U_{n} \sqrt{2}\left[\begin{array}{c}
\sin \left(\omega \mathrm{t}-\frac{\pi}{6}\right) \\
\sin \left(\omega \mathrm{t}-\frac{\pi}{2}\right)
\end{array}\right]
$$

In which $U_{n}$ is called the rated voltage. Although the RLC filter follows a quadratic equation according to equation (9), it is given in the following form for resonance control:

$$
\mathrm{C}_{\mathrm{r}}(\mathrm{S})=\frac{\mathrm{C}_{0}+\mathrm{C}_{1} \mathrm{~s}+\mathrm{C}_{2} \mathrm{~s}^{2}+\mathrm{C}_{3} \mathrm{~s}^{3}}{\left(\mathrm{~d}_{0}+\mathrm{d}_{1} \mathrm{~s}\right)\left(\mathrm{s}^{2}+\omega_{\mathrm{p}}{ }^{2}\right)}
$$

In which $d_{1}, d_{0}, c_{3}, c_{2}, c_{1}$ and $c_{0}$ are the parameters of the resonance control section and $\omega_{p}$ is the angular frequency of the controller. The application of these elements is fully explained in reference [4].

In the system above, the outputs of the resonance system which are the three-phase control voltages (the $\mathrm{U}_{m 13}$ reg and $\mathrm{U}_{\mathrm{m} 23 \_ \text {reg }}$ elements) are given in the following:

$$
\left[\begin{array}{c}
\mathrm{V}_{\mathrm{m} 1 \_ \text {reg }} \\
\mathrm{V}_{\mathrm{m} 2 \_ \text {reg }} \\
\mathrm{V}_{\mathrm{m} 3 \text { reg }}
\end{array}\right]=\frac{1}{3}\left[\begin{array}{ccc}
1 & 1 & 0 \\
-1 & 0 & 1 \\
0 & -1 & -1
\end{array}\right]\left[\begin{array}{c}
\mathrm{U}_{\mathrm{m} 12 \_ \text {reg }} \\
\mathrm{U}_{\mathrm{m} 13 \_ \text {reg }} \\
\mathrm{U}_{\mathrm{m} 23 \text { reg }}
\end{array}\right]
$$

\section{THE SIMULATION RESULTS}

This experiment has been conducted for a time period of 30 seconds. First, the wind blew on the turbine blades based on an unbalanced equation graph. Some diagrams were obtained from the turbine experiment in order to confirm the accuracy of its performance. The remaining time was spent on the changes of the three-phase load. The temporal procedure in different cases and the results simulated by MATLAB Simulink are given in the below.

The temporal procedure in different cases:

- 0 to 5 seconds, no load

- 5 to 9 seconds, resistive load added

- 9 to 14 seconds, inductive load added

- 14 to 18 seconds, resistive load reduced

- 18 to 23 seconds, load imbalance occurs

- 23 to 30 seconds, induction load fully removed.

Figure 7 illustrates the speed of the wind that blows on the wind turbine. It is evident that the imbalance of the wind speed occurs after $5 \mathrm{sec}-$ onds. Figure 8 shows the performance of the nonlinear control system of the blade angle at the time of imbalance; in a way that the angle between the turbine blades is changed linearly in time to prevent any damage that might be caused by the wind speed. The reaction of the system to the imbalance was observed to be linear in this figure.

Figure 9 illustrates the DC-bus output under different conditions when the voltage is fixed on a known value without any noise or disturbances; which usually sends the stability input to the con- 
verter. While analyzing dynamic systems, the system efficiency is typically studied which determines whether or not the control systems have been successful in achieving the best efficiency for the output. Figure 10 plots the diagram of the power qual-

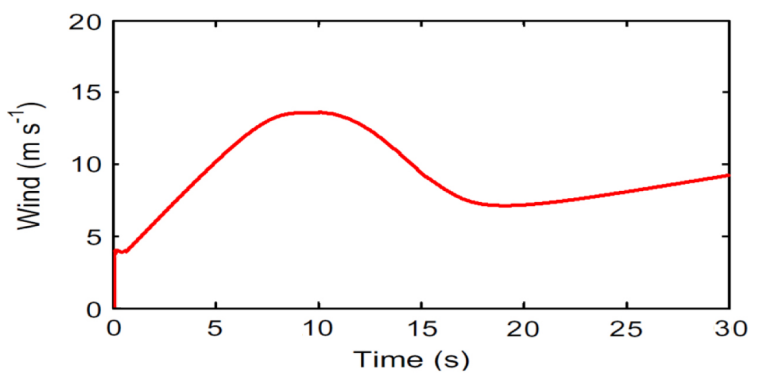

Fig. 7. The wind speed

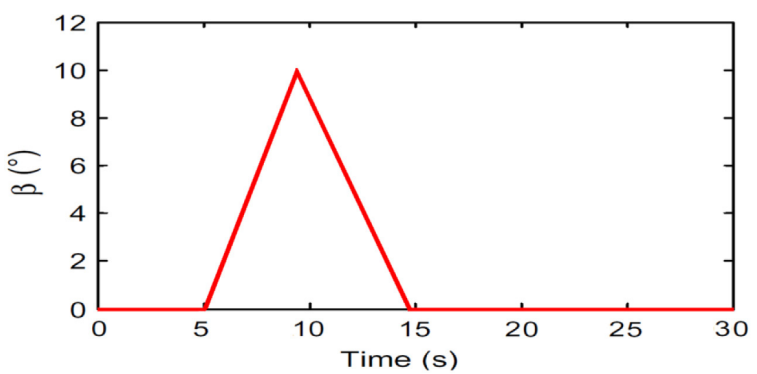

Fig. 8. Blade angle changes

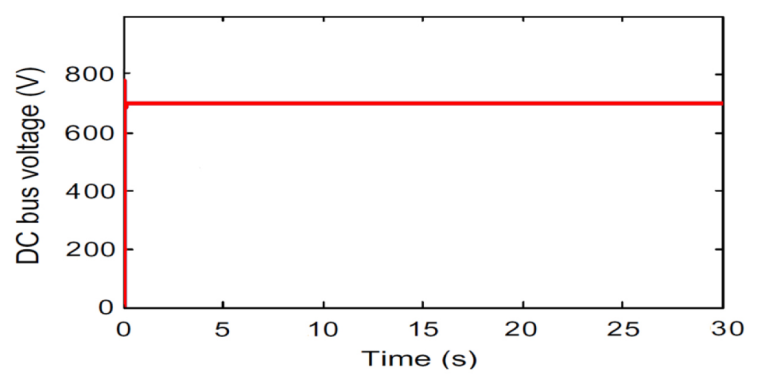

Fig. 9. The DC-link voltage

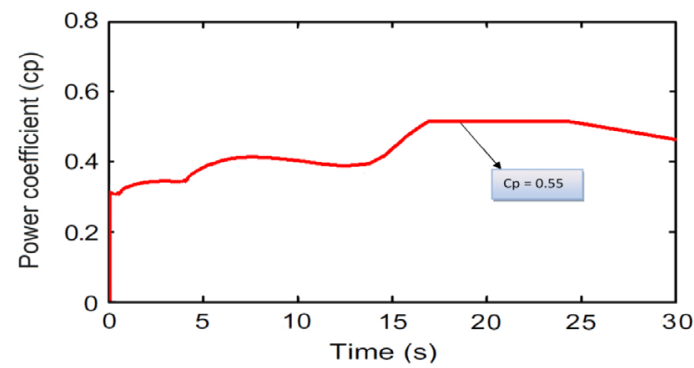

Fig. 10. The power quality factor ity factor which shows the value 0.55 . This value is significant in the control systems of a wind turbine.

Studying the results of the output power for the studied experiment in figure 11, we can clearly observe the changes of the power value under different

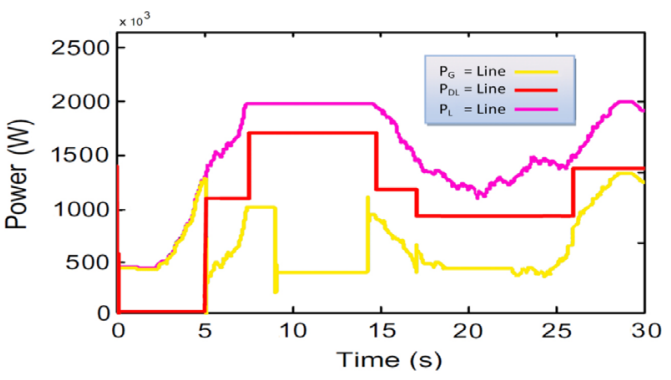

Fig. 11. Power changes in the normal mode.

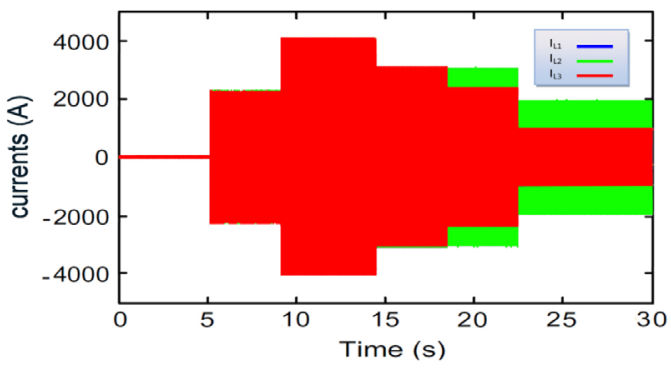

Fig. 12. Current changes under the studied conditions

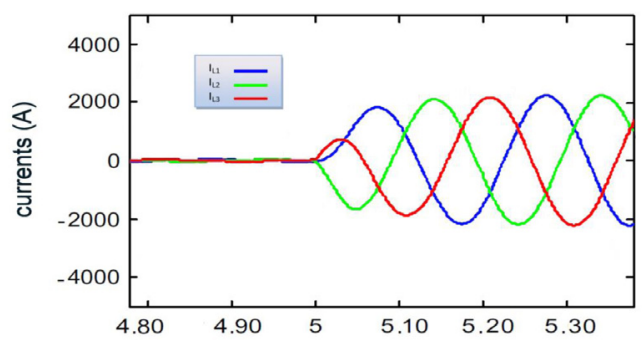

Fig. 13. Current changes in a specific time period of the experiment

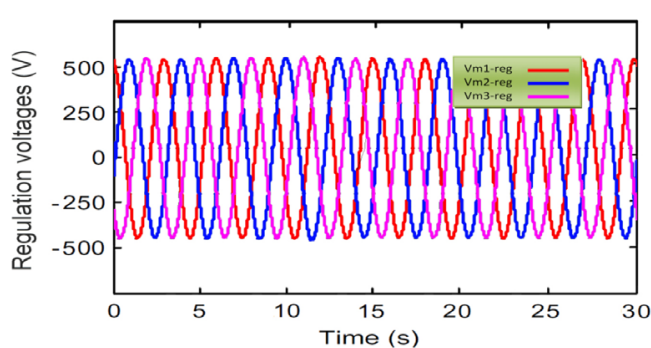

Fig. 14. Adjustment of output voltages under the studied conditions 


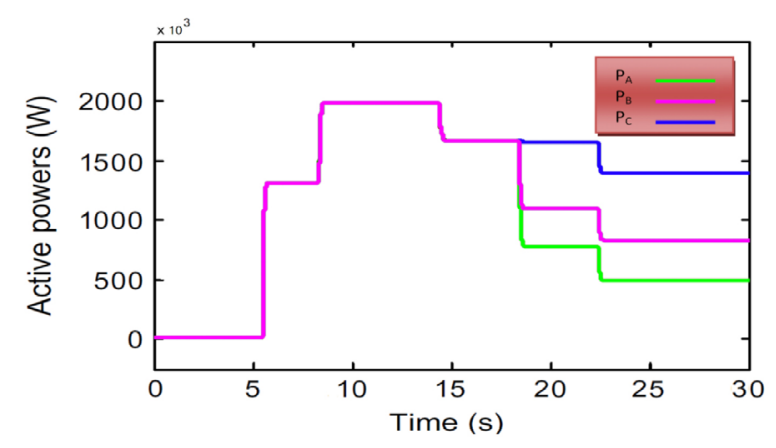

Fig. 15. The output active power under the studied conditions

conditions. As can be seen, the value of the output power is fixed on 2 megawatts in the figure, which confirms the precise performance of the control systems. Figure 12 illustrates the current changes in the system when the corresponding loads are added. These loads may or may not be balanced. This diagram shows a precise analysis of the system behavior. Moreover, figure 13 displays the behavior of the system currents under the studied conditions in a specific period of time. The stability of the output voltages adjusted under the studied conditions can easily be seen during the changes of the system currents using the behavior of a compliance system in figure 14. The active and reactive powers used in the system during load changes are illustrated in figures 15 and 16 . The active powers all follow a constant value at the time of the changes and the reactive powers react to the addition of the inductive loads.

\section{CONCLUSIONS}

In this paper, we studied a 2 megawatt autonomous PMSG wind turbine with balanced and unbalanced three-phase loads. The simulation results indicate that the proposed controllers precisely resolved the problems caused by the imbalance of the wind speed, switching harmonics and the changes of the three-phase loads. These controllers maintain the stability of the system and produce a fully controlled power in the output.

While designing filters and compliance controllers for adjusting the output voltage, we can see that the efficiencies of the nonlinear controllers and feedbacks in the system are very precise at the time of imbalance. They comply with the other components of the system and are completely effective and practical for the control systems of the turbine. The compliance of the nonlinear

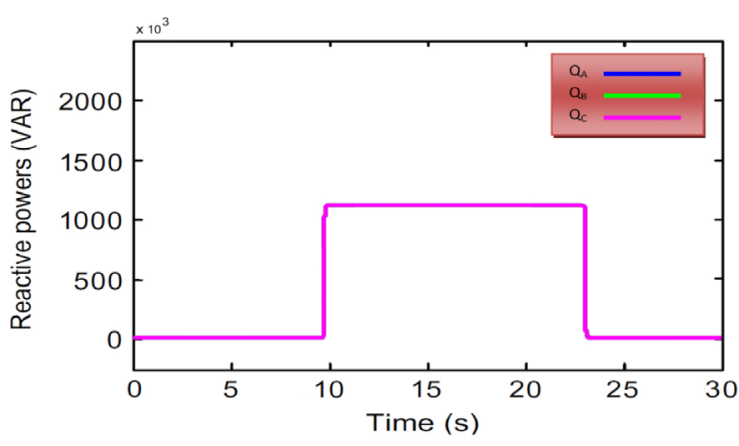

Fig. 16. The output reactive power under the studied conditions

controllers in PMSG strategies and the control of the blade angle by tuning these controllers is also an effective method for the controllers to react to the imbalance in order to control and protect the turbine and stabilize the output.

The simulation results in this study are applicable to a suburban site by taking into account all environmental factors. These results can guarantee the control of power supply for an isolated village which is not included in any power plant transmission line.

\section{REFERENCES}

1. Jackson G, Liu, Söffker D. Multivariable Control of Large Variable-Speed Wind Turbines for Generator Power Regulation and Load Reduction. IFACPapersOnLine Volume 48, Issue 1, 2015; 48(1), 544-549.

2. Kishor V, Ballal M S, Moharil R M. Investigation for Causes of Poor Power Quality in Grid Connected Wind Energy - A Review. Power and Energy Engineering Conference (APPEEC) 2012:34(1), 1-6.

3. Abdelkafi A, Masmoudi A, Krichen L. Experimental investigation on the performance of an autonomous wind energy conversion system. Int J Electr Power Energy Syst 2013; 44(1), 581-90.

4. Bhadane K, Ballal M S, Moharil R M. Wavelet transform based power quality analysis of grid connected wind farm - An investigation of Power Quality Disturbances. Advances in Electrical Engineering (ICAEE) International Conference on 2014; 84(8), 1-6.

5. Masmoudi A, Krichen L, Ouali A. Voltage control of a variable speed wind turbine connected to an isolated load: experimental study. Energy Convers Manage 2012; 59, 19-26.

6. Dincer F. The analysis on wind energy electricity generation status, potential and policies in the world. Renew Sust Energy Rev 2011; 15(9), 5135-42. 
7. Masmoudi A, Abdelkafi A, Krichen L. Electric power generation based on variable speed wind turbine under load disturbance. Energy 2011; 36(8), 5016-26.

8. Battaiotto PE, Mantz RJ, Puleston PF. A wind turbine emulator based on a dual DSP processor system. Contr Eng Pract 1996; 4(9), 1261-6.

9. Camblong H, Martinez de Alegria I, Rodriguez M, Abad G. Experimental evaluation of wind turbines maximum power point tracking controllers. Energy Convers Manage 2006; 47(18-19), 2846-58.

10. González LG, Figueres E, Garcerá G, Carranza O. Maximum-power-point tracking with reduced mechanical applied to wind-energy-conversionsystems. Appl Energy 2010; 87(7), 2304-12.

11. Ganji E, Mahdavian M. A Controlling Method of DFIG-Based Wind Turbine for Stability Improvement of Power Delivery to the Power Grid. Journal of Electrical Systems 2016:12(4), 591-611.

12. Du W, Wang HF, Cheng S, Wen JY. Robustness of damping control implemented by energy storage systems installed in power systems. Int J Electr Power Energy 2011; 33(1):35-42.

13. Kesraoui M, Korichi N, Belkadi A. Maximum power point tracker of wind energy conversion system. Renew Energy 2011; 36(10), 2655-62.

14. Singh M, Khadkikar V, Chandra A. Grid synchronisation with harmonics and reactive power compensation capability of a permanent magnet synchronous generator-based variable speed wind energy conversion system. IET Power Electron 2011; 4(1), 122-30.

15. Melício R, Mendes VMF, Catalão JPS. Power converter topologies for wind energy conversion systems: Integrated modeling, control strategy and performance simulation. Renew Energy 2010; 35(10), 2165-74.

16. Rodriguez J, Rivera M, Kolar JW, Wheeler PW. A review of control and modulation methods for matrix converters. IEEE Trans Ind Electron 2012; 59(1), 58-70.
17. Zhong L, Rahman MF, Hu WY, Lim KW, Rahman MA. A direct torque controller for permanent magnet synchronous motor drives. IEEE Trans Energy Convers 1999; 14(3), 637-42.

18. Holdsworth L, Wu XG, Ekanayake JB, Jenkins N. Comparison of fixed speed and doubly-fed induction wind turbines during power system disturbances. IET Power Electron 2003; 150(3), 343-52.

19. Li X, Su M, Sun Y, Dan H, Xiong W. Modulation strategies based on mathematical construction method for matrix converter under unbalanced input voltages. IET Power Electron 2013; 6(3), 434-45.

20. Singh N, Agrawal V. A review on power quality enhanced converter of permanent magnet synchronous wind generator. Int Rev Electr Eng (IREE) 2013; 8(6), 1681-93.

21. Chen Z, Spooner E. Voltage source inverters for high-power, variable-voltage DC power sources. IEEE Proc Gener Transm Distrib 2001; 148(5), 439-47.

22. Xia C, Zhao J, Yan Y, Shi T. A novel direct torque control of matrix converter-fed PMSM drives using duty cycle control for torque ripple reduction. IEEE Trans Ind Electron 2014; 61(6), 2700-13.

23. Ponmani C, Rajaram M. Compensation strategy of matrix converter fed induction motor drive under input voltage and load disturbances using internal model control. Int J Electr Power Energy Syst 2013; 44(1), 43-51.

24. Singh B, Sharma S. SRF theory for voltage and frequency control of IAG based wind power generation. IEEE Int Conf Power Syst ICPS 2009, 2009:1-6.

25. Han J. From PID to active disturbance rejection control. IEEE Transactions on Industrial Electronics 2009; 56(3), 900-906.

26. Jiang L, Wu Q.H. Nonlinear adaptive control via sliding-mode state and perturbation observer. IEE Proceedings - Control Theory and Applications 2002; 149(4), 269-277. 